\title{
Designing a quick fix shutter for auto-disinfecting scan glass surface in biometric scanners
}

\author{
Deepalekshmi Ponnamma ${ }^{1}$, Mohammad Talal Houkan ${ }^{1}$, Muni Raj Mourya ${ }^{1}$, Noora Al-Thani ${ }^{2}$ \\ ${ }^{1}$ Center for Advanced Materials, Qatar University, P O Box 2713, Qatar \\ 2 Young Scientist Center, Qatar University, P O Box 2713, Qatar
}

\begin{abstract}
Fingerprint scanners are significant devices in professional life, and its contamination can be potential sources of COVID 19 transmission. Manual disinfection of the fingerprint scanner after every single use is time consuming and even can adversely affect its electronics/functioning. Thus, with an aim to prevent the spread of infectious disease by cross contamination and implement the safe use of fingerprint scanner, we have developed a smart quick fix technology for automatic disinfection of finger print scanner glass after every single use. The smart portable top mount assembly uses two different disinfecting methods that ensures higher degree of disinfection. The disinfection is based on the simultaneous ultraviolet (UV) and heat treatment for a specific short time, and required to kill all the viruses on the scan glass surface. Moreover, developing this disinfecting technology with a universal design that can be fitted to any finger print scanner irrespective to its size, makes it a novel idea.
\end{abstract}

\section{Objectives}

$>$ Fabrication of smart quick fix top mount shutters to disinfect the biometric scanner glass surface.

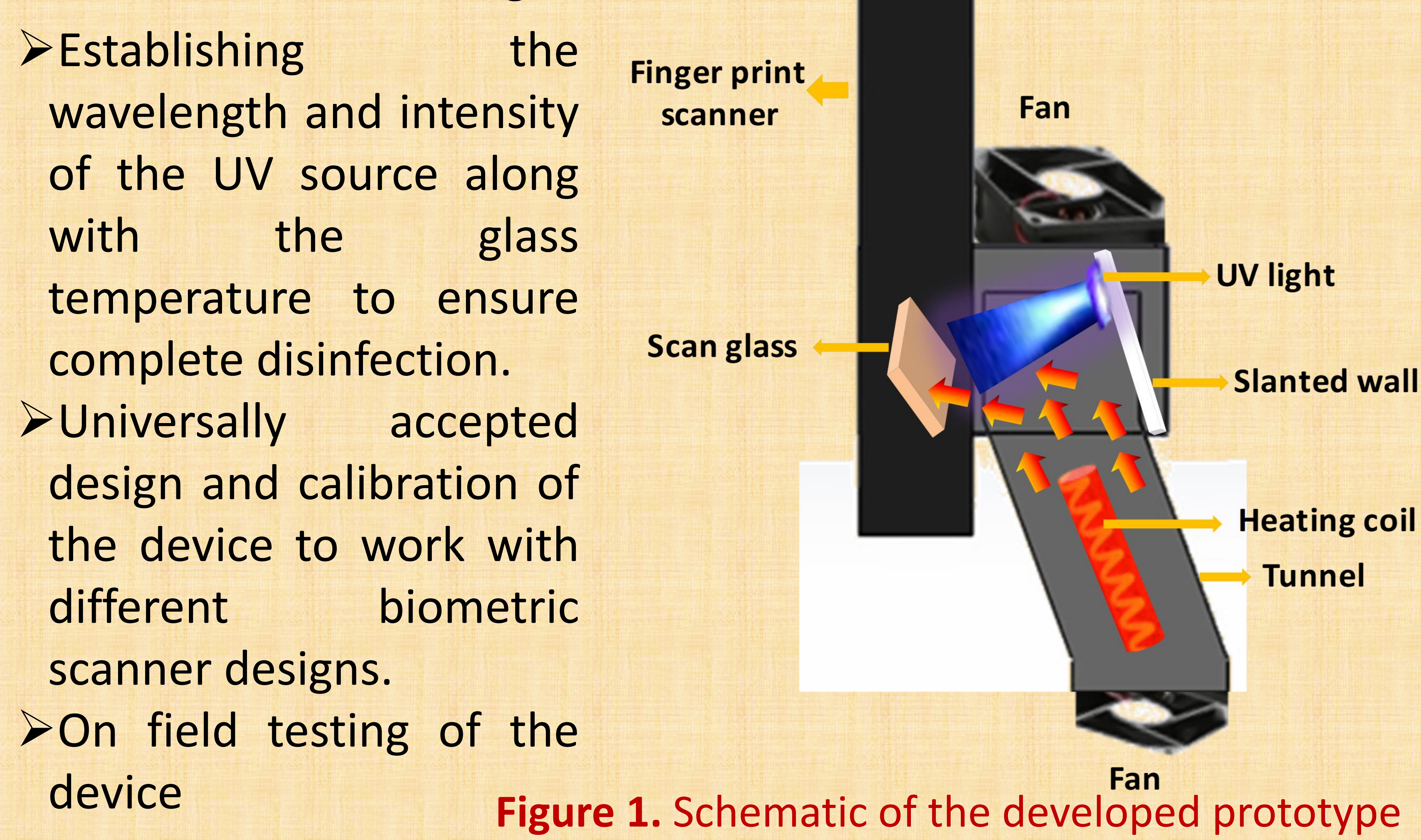

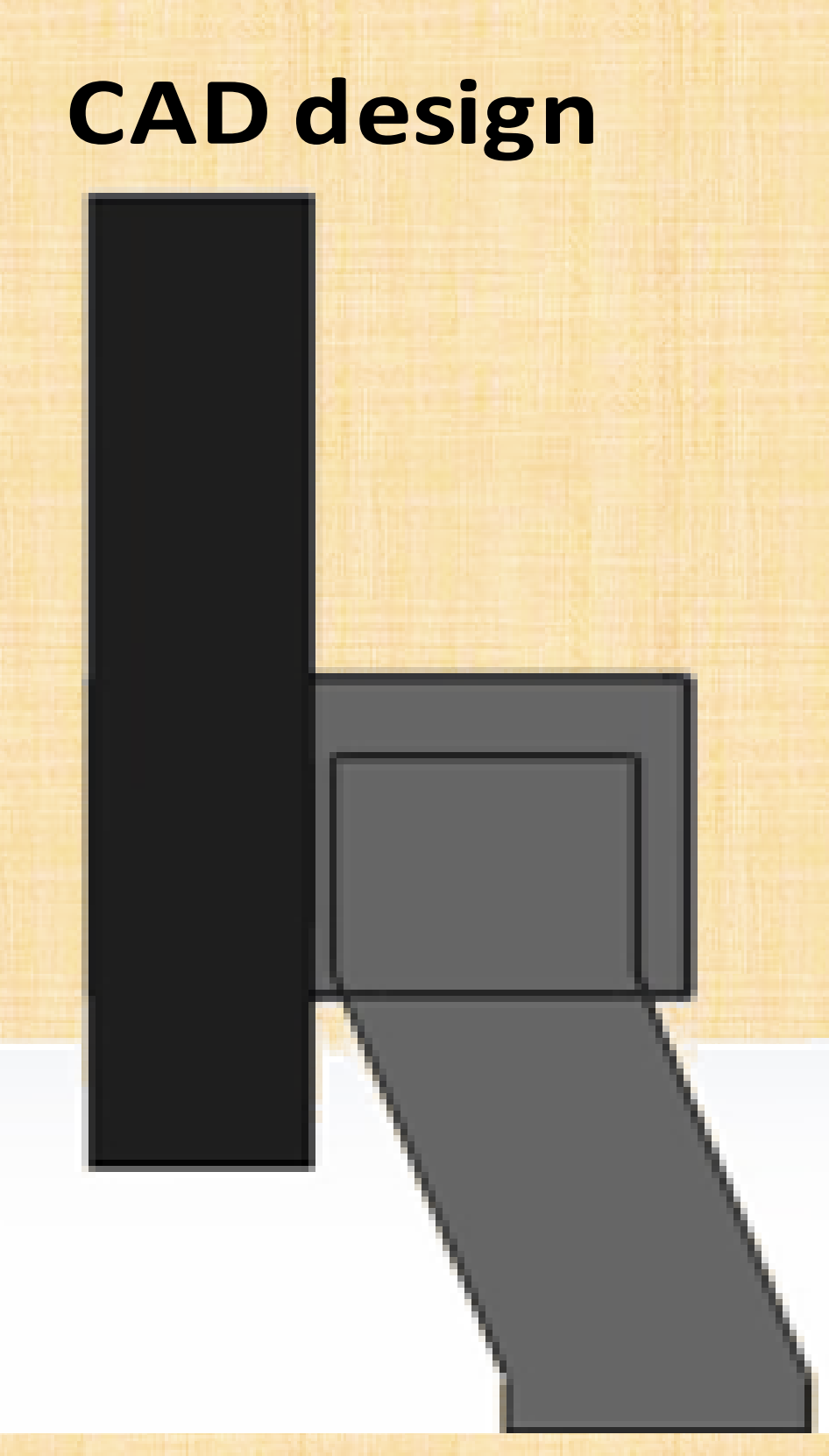

3D Printed

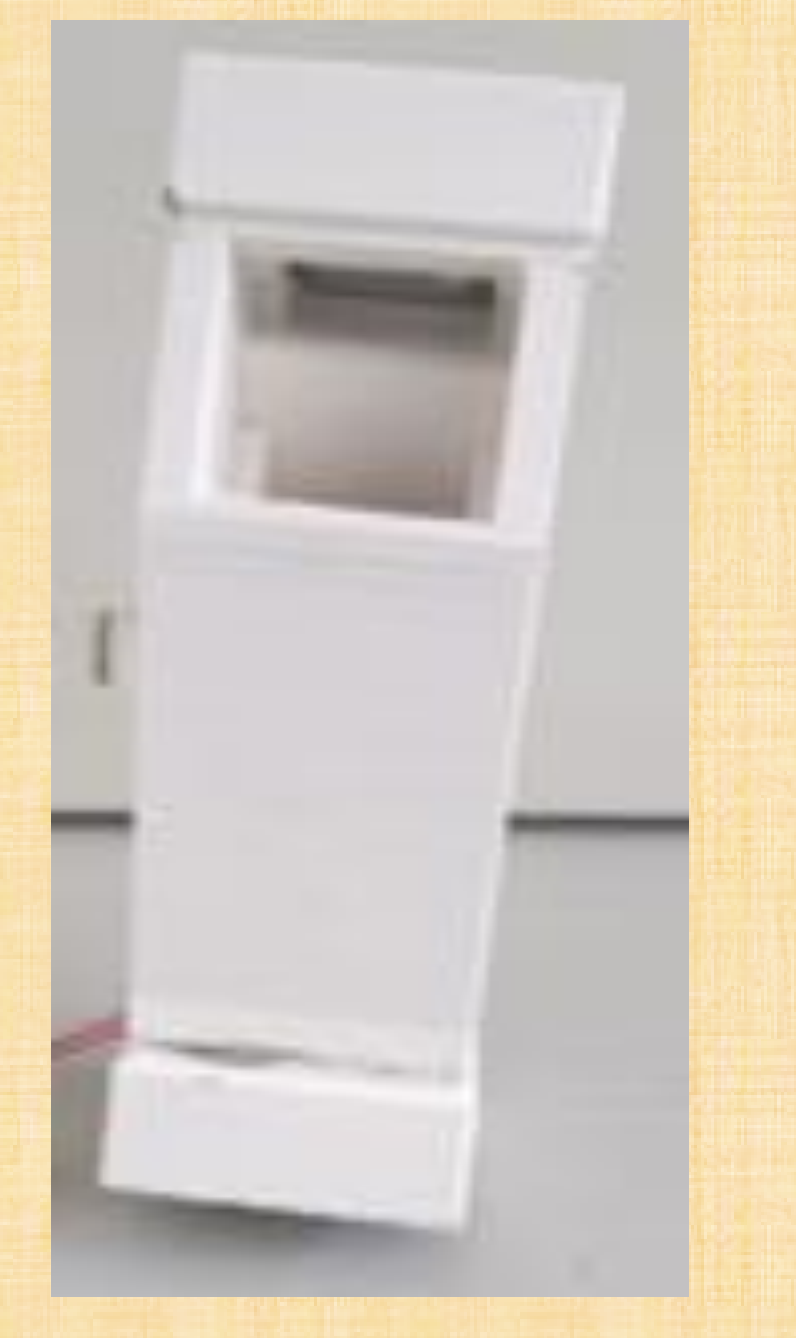

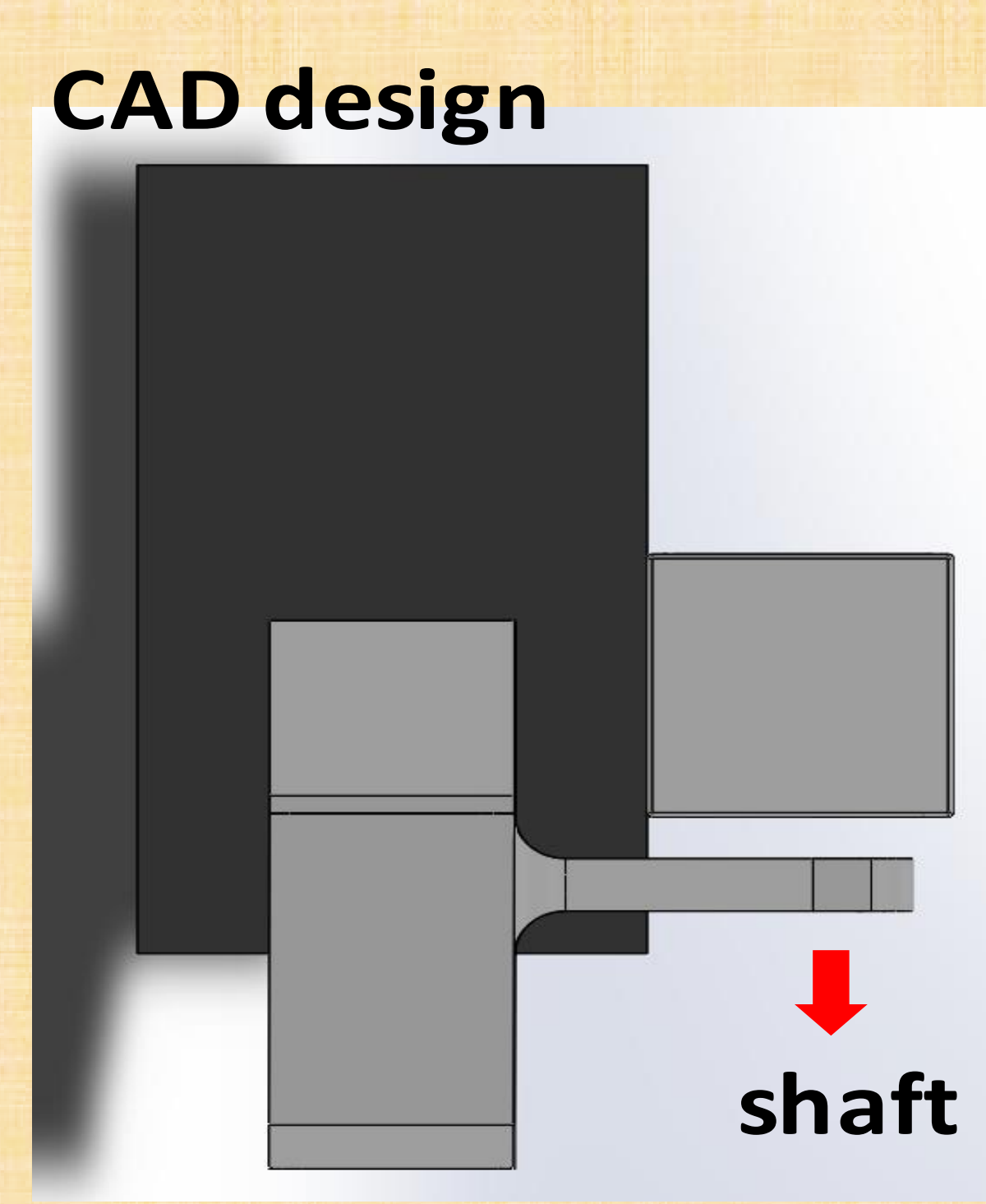

3D Printed

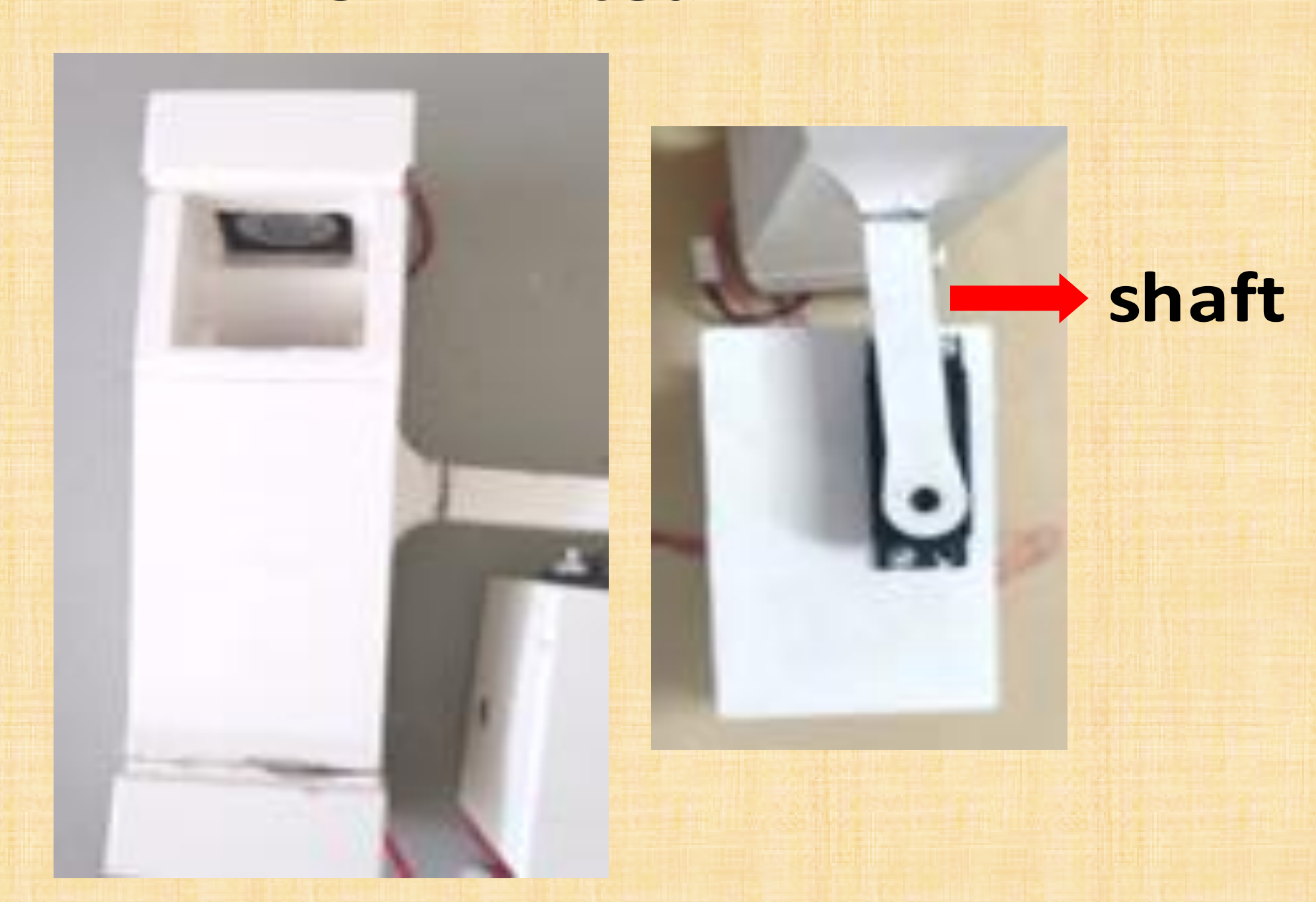

Figure 2. CAD design of the disinfecting unit and its corresponding 3D printed parts.

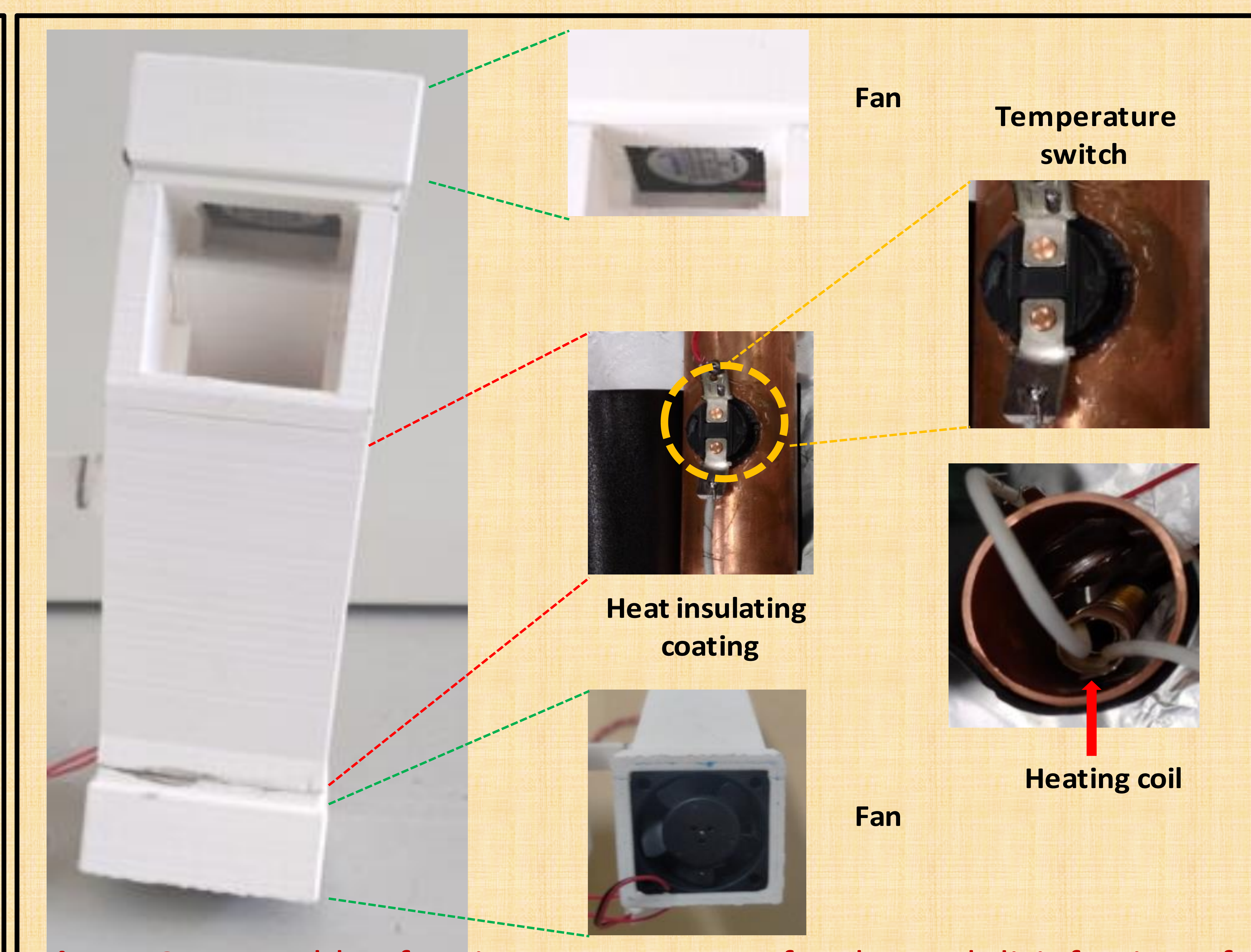

Figure 3. Assembly of various components for thermal disinfection of the scan glass.

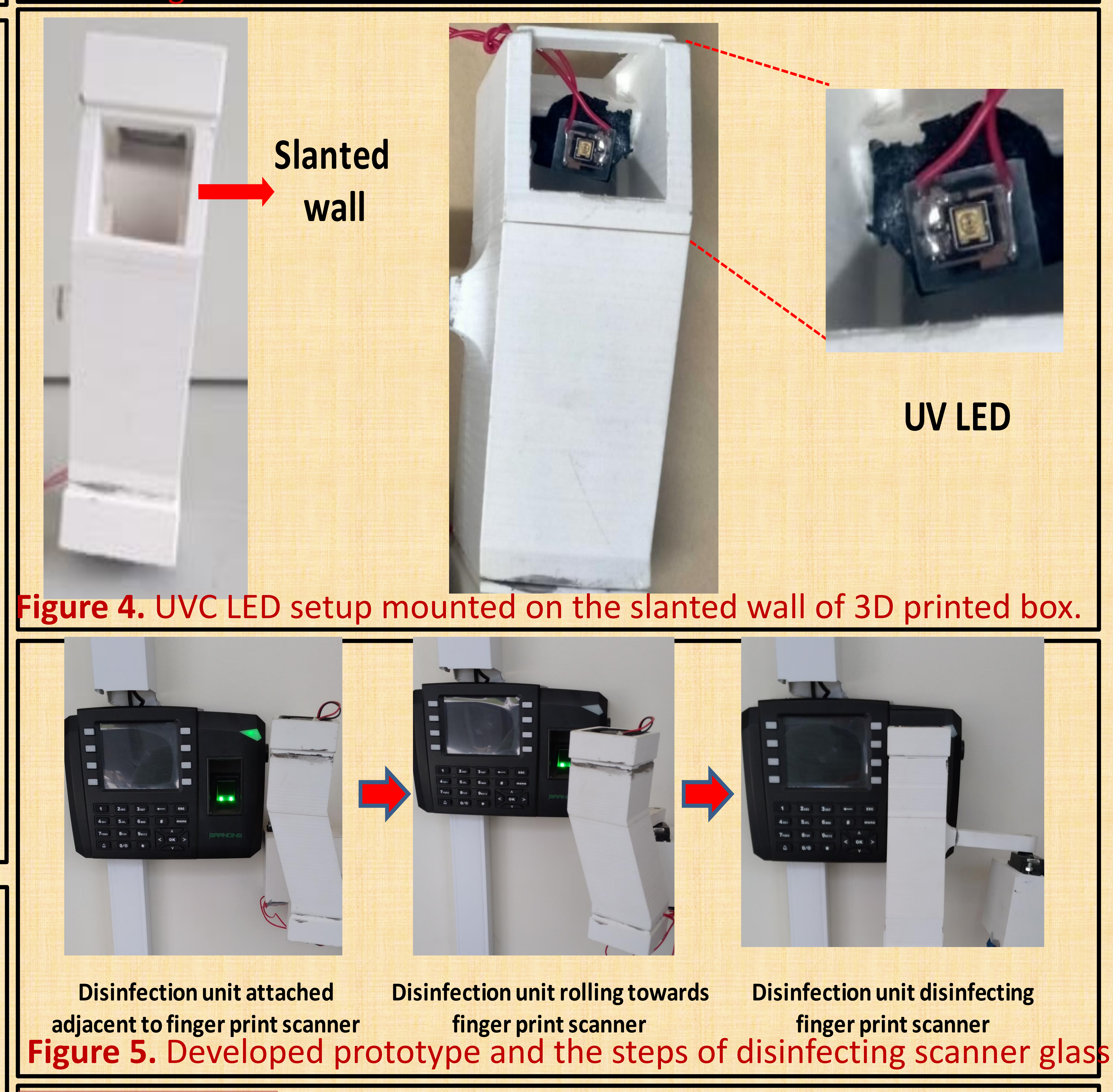

\section{Conclusions}

Smart and portable top mount assembly uses two different disinfecting methods that ensures higher degree of disinfection. The disinfection is demonstrated based on the simultaneous ultraviolet (UV) and heat treatment for a specific short time, and required to kill all the viruses on the scan glass. The technology is developed with a universal design that can be fitted to any finger print scanner irrespective to its size.

\section{Acknowledgement}

This research is made possible by RRC grant RRC-2-114 from the Qatar National Research Fund (a member of Qatar Foundation).

\section{References}

Casini, B.; Tuvo, B.; Cristina, M.L.; Spagnolo, A.M.; Totaro, M.; Baggiani, A.; Privitera, G.P. Int. J. Environ. Res. Public Health 2019, 16, 3572.

de Groot, T, Chowdhary, A, Meis, JF, Voss, A.. Mycoses. 2019; 62:408- 412. 